\title{
PULSATILE DRUG DELIVERY SYSTEM: A FORMULATION APPROACH FOR TREATMENT OF DISEASES
}

\author{
PASHAM SOWMYA*, VENKATESH DP, SUJIT NAYEK
}

Department of Pharmaceutics, Acharya and BM Reddy College of Pharmacy, Soldevanahalli, Hesaraghatta Road, Bengaluru 560107, Karnataka, India

Email: pashamsowmya9@gmail.com

Received: 25 Jan 2020, Revised and Accepted: 23 Mar 2020

\begin{abstract}
In the field of pharmaceutical technology, pulsatile drug delivery systems are gaining popularity as these devices deliver the right dose at a specific location at a particular time. Some of the conditions under which pulsatile drug delivery system is positive include duodenal ulcer, cardiovascular disease, arthritis, asthma, diabetes, neurological disorder, cancer, hypertension, and hypercholesterolemia. Pulsatile drug delivery systems are essentially time-controlled drug delivery systems in which the lag time is regulated independently of environmental factors such as pH, enzymes, gastrointestinal motility, etc. The theory justification for the use of pulsatile release is for drugs where a continuous release of drugs is not needed, i.e. a zero-order release. Drug administration in chronopharmacotherapy is coordinated with biological rhythms to achieve full therapeutic effect and minimize harm to the patient. This drug delivery system is designed to distribute drugs in accordance with body clock. The pulse must be designed in such a way as to achieve a total and rapid release after the lag time.
\end{abstract}

Pulsatile drug delivery is therefore one device that provides strong promises of benefit to patients suffering from chronic conditions such as arthritis, asthma, hypertension by delivering medication at the right time, right place and in appropriate quantities. In recent pharmaceutical applications involving pulsatile delivery; multi-particulate dosage forms (e. g. pellets) over single-unit dosage forms are gaining more popularity. On the basis of methodologies, various pulsatile technologies have been developed, including ACCU-BREAKTM, AQUALON, CODAS $®$, PRODAS $®$, SODAS $®$, MINITABS $®$, DIFFUCAPS $®$, OROS $®$ etc.

Keywords: Pulsatile drug delivery, Chronotherapeutics, Mini tablets, PDDS technology

(C) 2020 The Authors. Published by Innovare Academic Sciences Pvt Ltd. This is an open access article under the CC BY license (http://creativecommons.org/licenses/by/4.0/) DOI: http://dx.doi.org/10.22159/ijcpr.2020v12i3.38328. Journal homepage: https://innovareacademics.in/journals/index.php/ijcpr

\section{INTRODUCTION}

The largest segment of the overall drug delivery market is the delivery of oral drugs. It is the most favoured drug administering road. The oral controlled-release systems display a typical pattern of drug release in which the concentration of the medication is retained for an extended period of time in the therapeutic window, thereby ensuring continuous therapeutic action. There are certain conditions under which such a release pattern after a lag time is not appropriate for demanding release of a drug. They need, in other words, a pulsatile drug delivery system (PDDS). The pulsatile mechanism is gaining a lot of attention because after a given lag time, the drug is released completely. The pulsatile delivery of drugs is time-and site-specific delivery of drugs, thereby providing spatial and temporal distribution and increasing patient compliance. The pulsatile delivery of drugs is characterized as the rapid and transitory release of certain molecules.

Due to poor drug efficacy, the incidence of side effects, and frequency of administration to conventional drug preparations, many traditional drug dosage forms are undergoing replacement by second-generation, modified drug release dosage forms. During the early 1990s, the second-generation modified release drug preparations achieved continuous and constant drug delivery efficiency, in which consistent or sustained drug production decreased levels of "peak and valley" drug concentration in the blood, promoted drug efficacy and reduced adverse effects. Recent studies also show that the biological rhythm of the body can affect normal physiological function, including gastrointestinal motility, gastric acid secretion, gastrointestinal blood flow, renal blood flow, urinary $\mathrm{pH}$, heart rate, drug-protein binding and liver enzymatic activity, and biological functions such as heart rate, blood pressure, body temperature, Blood plasma concentration, intraocular strain, stroke length and platelet aggregation. Most functions of the organ differ with the time of day, particularly when rhythmic and temporal patterns occur in the manifestation of the disease. Symptoms of many diseases have accompanied the biological rhythm of the body, such as bronchial asthma, myocardial infarction, angina pectoris, hypertension, and rheumatic disease. Day night variations in asthmatic dyspnoea and occurrence of myocardial infarction arise throughout the early hours of the morning. A biological-rhythmbased chronodelivery device is a state-of-the-art drug delivery technology; chronomodulated DDSs not only increase safety and efficacy rates but also improve overall drug performance. Currently under development the time-controlled role of third generation DDSs is finding application in new and improved therapies for diseases. Biological rhythms can be extended to pharmacotherapy through the adoption of a dosage type that synchronizes drug concentrations with disease activity rhythms [1, 2].

Chronotherapy refers to a method of treatment in which the release of in vivo medications is scheduled to match disease cycles to maximize clinical success and reduce side effects. Pulsatile drug delivery systems may be divided into site-specific systems where the drug is released at the desired location within the intestinal tract (e. g., colon) or time-controlled devices where the drug is released after a well-defined period of time [3].

Medication-release mechanism from the pulsatile drug delivery system

PDDS drug-release mechanism can occur in the following ways:

Diffusion: As molecules getin contact with aqueous liquids in the gastrointestinal tract, liquid diffuses into the inside of the sample and the resulting drug solutions scatter across the release coat to the outside.

Erosion: Some coatings designed to erode gradually with time, result in the release of drug contained within the particle.

\section{Osmosis:}

It is possible to build up an osmotic pressure inside the particle whe $\mathrm{n}$ water allows it to enter under the right conditions [4]. 


\section{Necessities of PDDS}

Pulsatile drug delivery system is gaining lot of interest to deliver the drugs. The needs of this novel drug delivery system such as, (a) therapy of disorders including heart problems throughout sleep, early in the morning asthma or joint stiffness attacks, etc., whereby disease pathophysiology is regulated by bodies circadian, (b) able to quickly administer first-pass metabolism, e. g. peptides and proteins, (c) by decreasing consumption of the medicines in the body, (d) Using PDDS, distal GIT sections such as colon can be targeted, (e) quick $\mathrm{t} 1 / 2$ medications, e. g. $\beta$-adrenergic blockers, (f) confined treatment condition in which medication should be given to the inflammation site for optimal therapeutic advantages with limited adverse reactions such as inflammatory disease of intestine without any loss in medication, (g) drug protection from the acidic stomach environment, (h) protection of the stomach mucus layer from certain medications such as peptide drugs [5-7].

\section{Advantages of PDDS}

Pulsatile drug delivery system is a novel drug delivery system for a lot of reasons including, increased day or night time operation, reduced the side effects, reduced dose size and frequency of dosage, increased communication with patients, reduced costs, drug adapts to body activity and infection circular flow, drug targeting specific location like colon, defence against distracting drugs against mucosa, distribution of medication to an appropriate GIT position such as colon, drug loss prevention because of high hepatic metabolism such as peptides and proteins, fewer side effects, less dumping threat, flexibility in designing the drug delivery system, improved bioavailability and compliance for patients [8-9].

\section{Disadvantages of PDDS}

Despite these benefits, PDDS have certain constraints, such as limited capacity of medication loading or insufficient product launch, higher prices for output, many customizable techniques, risk in development repeatability and productivity, production of batch processes and IVIVC unpredictable [10,11].

\section{Methods of pulsatile drug delivery system}

The PDDS can be divided into 3 categories such as, pulsatile launch scheme moment-checked, stimuli inducing and externally regulating.

\section{Pulsatile launch scheme moment-checked}

Pulsatile release is achieved in time-controlled System for the delivery of drugs to imitate circadian rhythm after specific time period. Such a System for the delivery of drugs comprises 2 components: One of the instant launch types and one of the pulsed launch types.

Similar methods which can be used in timely pulsatile launch systems:

\section{Input coating schemes with a breakable surface}

Such technologies comprise of such an external launch which regulates indigestible, yet impervious, water which is subject to change without notice subject for mechanically induced breakdown. Many Hard gel capsule and tablet main devices core have recently been identified, all covered by internal swellable external sheet. In the reservoir, osmotic effervescent additives can achieve film breakup, including swelling. Through optimization, the launch of drugs can be achieved at a general period of time. It is possible to obtain time dependent active ingredient release by maximizing the width of the outer coat $[12,13]$.

\section{System of capsule shaped with control plug for launch}

The release control plug-in between instant liberation is included in the all devices as well as the pulsed launch compartment. The cap dissolve rapidly when in contact with watery fluids, releasing the immediate release portion the pulsed release portion is followed. A plug implanted in to the body indicates the time delay [14].

\section{Pulsatile systems induced through stimulation}

In these systems, every physiological variable such as temperature or other chemical signals activates the drug following stimulation.

\section{Temperature induced systems}

Thermo responsive systems of hydrogel for pulsatile release have been built. In these installations, Product launch to reaction to a temp which synthesizes the launch of medications throughout the inflamed state, the polymer Subject to swelling or deswelling $[13,15]$.

\section{Pulsatile system induced by chemical stimuli}

\section{Glucose-related tools for launch}

Insulin rhythmic rises in the body's glucose levels in diabetes mellitus, which involve insulin injection at the right time. Several systems that can react to changes in concentration of glucose have been developed. One system of this kind includes immobilized Hydrogel-sensitive glucose oxidase, glucose oxidase. When the glucose blood concentration increases, glucose oxidase transforms glucose into gluconic acid, which changes the $\mathrm{pH}$ of the system. The change in $\mathrm{pH}$ causes that polymer to swell, leading to insulin release. Insulin reduces blood sugar levels because of its action and thus the level of gluconic acid thus decreases and the body switches to the deswelling mode and increasing the release of insulin. Types of polymers that are immune to $\mathrm{pH}$ include $\mathrm{N}, \mathrm{N}$ dimethylaminoethyl methacrylate, chitosan, polyol, etc [16].

\section{Pulse release caused by inflammation}

Inflammation occurs at the injured sites when physical or chemical pressure is obtained, such as, trauma, fracture, etc. A group of researchers focused on the hydroxyl radicals that were induced by inflammation and designed system of drug delivery that responded and degraded in a limited way. Hyaluronic acid (HA) was used in which hyaluronidase and free radicals actually destroy. However, Once HA is injected at inflammatory sites; degradation by hydroxyl radicals is typically dominant and rapid. Therefore, patients with Enlarged spleen cases like rheumatoid arthritis may be treated as new implantable drug delivery systems with anti-inflammatory medication integrated HA gels [17].

\section{Drug release from smart gels that respond to concentration of antibodies}

In the body there are numerous types of bioactive compounds. Recently, novel gels have been developed that responded to the shift in bioactive compound concentration to change the features of their swelling/deswelling. The complex formation of antigen-antibody as the cross-linking units in the gel has been given special attention since this interaction is very general $[15,18]$.

\section{Unit of drug delivery responsive to $\mathrm{pH}$}

Pulsatile drug delivery system comprises two elements, one which is a form of in response to increase in $\mathrm{pH}$, immediate release the other is a pulsed release of the drug. The advantage of having different $\mathrm{pH}$ conditions in different parts of the gastrointestinal tract was taken in the case of a pH dependent system. Examples of $\mathrm{pH}$ dependent polymers are cellulose acetate phthalate, poly acrylate, sodium carboxy methylcellulose. Such polymers are used as coating materials in this system for introduction of drugs into the small intestine [19].

\section{Externally regulating}

Externally controlled systems in which external stimuli such as magnetism, ultrasound, electrical influence or irradiation may also be used to release drugs in a pulsating manner. By magnetic means controlled system installation includes the magnetic pearls of implants. Drugs release occurs due to magnetic beads while applying the magnetic field. For the production of insulin dependent on alginate spheres in vitro, a group researchers developed different formulation. The ultrasonic waves induce the degradation of the polymer matrix in the case of ultrasonically modulated devices, modulating the release of drugs. A group of researchers measured the ultrasound effect of $(1 \mathrm{MHz})$ on bovine insulin copolymer system levels of ethylene vinyl, drug and alcohol delivery systems are released and observed a blood glucose levels drop sharply after ultrasonic waves were applied [20]. 


\section{Different approaches to the delivery of pulsating drugs}

\section{Osmosis based system}

This device contains capsules that are semi-permeable to the membrane. An insoluble tube, an osmotic active drug and active agent formula in the capsule is kept inside. The semi permeable membrane allows gastric fluid to come into contact with GI fluid as the capsule shell comes into contact. As a result, the osmotic pressure and the plug swells are created. When the pressure exceeds the membrane's tensile strength, it bursts and the time taken to break the membrane is called the lag time [21-25].

\section{Capsule based system}

The Pulsincap module is one of the most widely used pulsatile capsule based systems. This is an insoluble capsule that contains the reservoir of the drug [26]. Different viscosity levels of hydrogels such as hydroxypropyl methyl cellulose, polymethyl methyl acrylate, polyvinyl acetate and polyethylene oxide are polymers used to model these tubes. Superdisintegrant have also been used to create a capsule-based system which included a drug, a swelling agent, as well as a ruptured polymer layer [27-31].

\section{System with change of permeability of the membrane}

A type of sigmoid breakout is collected through medication-coated pellet centers and copolymer-coated succinic acid. Throughout the medium, succinic acid is consumed by liquid. Its absorption of the polymer film tends to increase within the medication as well as the chemical solution. Actually, acrylic polymers are permeable and water absorbed [32-35]. In fact, with quaternary ammonium groups, the presence of multiple volume conter-ionscan controls osmotic pressures for plastic composites and liquid absorption. Eudragit is commonly used for this purpose because it includes in the polymer side chain a positive polarized quaternary ammonium group, always followed by negative hydrochloride counter ions. Because of the Sulfate group lipid soluble character, it promotes contact with water by the polymer. As just a consequence, a polymer's osmotic pressure was altered as well as the liquid permeates in to the effective core. The drug permeability of the Eudragit film is also significantly affected by a pellet essence includes a small quantity in sodium acetate. This results in the release of the whole dose within a couple of minutes. This device is used to build a center that includes acids [36-42].

\section{Herbal drugs containing PDDS}

Herb formulas were gradually become more acceptable across the globe due to various their particular effectiveness, few side effects or safety [43]. Numbers of research results have been recorded in the format of lag-period formulas comprising of Chronotherapy pharmaceutical products. Adhatodavasica (vasaka powder) were built between Sarfaraz and Joshi, tablets formulation in the early morning to prevent asthma attack. The immediate release center tablets of raw vasaka material has also been formulated evaluated or covered as just an inner surface of ethyl cellulose as well as an external enteric coating layer of Eudragit S100. The formulation dissolution study covered For $25 \% \mathrm{w} / \mathrm{w}$ of ethyl cellulose and $2.5 \%$ $\mathrm{w} / \mathrm{w}$ of Eudragit S100, there is no secretion in $0.1 \mathrm{~N} \mathrm{HCl}$ for $2 \mathrm{~h}$ but $91.46 \%$ of the drug was produced at $\mathrm{pH} 6.8$ at a end of $10 \mathrm{~h}$. A study reports showed an appropriateness of such a delay of asthma Chronotherapy of vasaka formula [44-47].

Table 1: Diseases involving the injection of pulsating drugs

\begin{tabular}{|c|c|c|c|}
\hline Diseases & Chronological behaviour & Drugs used & Ref. \\
\hline Ulcerative peptic & $\begin{array}{l}\text { In the afternoon and night, acid secretion is } \\
\text { strong. }\end{array}$ & H2 blockers & $\begin{array}{l}{[45,} \\
48]\end{array}$ \\
\hline cancer & $\begin{array}{l}\text { During each daily phase, the blood flow to } \\
\text { tumors is three times greater during the } \\
\text { phase of the daily }\end{array}$ & Cannabinoid compounds of vinca, taxanes & \\
\hline Ulcerative duodenal & $\begin{array}{l}\text { The generation of gastrointestinal acid was } \\
\text { the strongest during nighttimes, whereas } \\
\text { abdomen or intestine cell proliferation or } \\
\text { intestine clearing are mostly slow at night. }\end{array}$ & Proton pump inhibitors & \\
\hline Physiological impairment & $\begin{array}{l}\text { The basic epilepsy Neurobiology of the } \\
\text { infection and the identification for convulsive } \\
\text { episodes in behaviour. }\end{array}$ & MAO-B inhibitor & \\
\hline Hypercholesteremia & $\begin{array}{l}\text { The synthesis of cholesterol is generally high } \\
\text { at night than during the day }\end{array}$ & Receptors of HMG CoA pyruvate dehydrogenase & \\
\hline Mellitus hyper glycaemia & Blood glucose increase upon meals & Sulfonyl urea, glucose & \\
\hline Arthropathy & Stress levels are rising during night. & Glucocorticoids, Pain relievers & \\
\hline Back and heart disease & $\begin{array}{l}\text { During the sleep cycle Bp is at its lowest and } \\
\text { in the morning it rises steeply }\end{array}$ & $\begin{array}{l}\text { Sodium azide, receiver of ion channels, agonists of } \\
\text { ACE }\end{array}$ & \\
\hline Asthma & $\begin{array}{l}\text { Attack temperatures during night time or in } \\
\text { the early morning }\end{array}$ & Antagonist of B2, allergy medicines & \\
\hline exposure to condition deficient & Boost in fluoxetine DOPA in the afternoon & Methyl phenidat & \\
\hline
\end{tabular}

\section{Marketed drug delivery technologies}

Different marketing technologies, Pulsincap TM, Diffucap $®$, CODAS $\AA$, OROS $\AA$, PRODAS $\AA$, Ritalina $\AA$, Uniphyl $\AA$ and Opana $\AA$ have been developed.

\section{Pulsincap TM technology}

Pulsincap device consists of a non-disintegrating half-capsule body enclosed with a hydrogel plug at the open end, which is filled with a water-soluble shield. Its module was packed with such a polymer cell lysis to avoid the issue of intestinal selective cleaning. If this pipe comes into contact with that of the disintegration liquid, this rises; after an early hour, the connector troops the capsule itself and releases the content readily. Another formulation solution was a bead or granule with such a four-layer round surface comprising of such a seed, a drug, a swell agent (e. g., sodium starch glycolate or carboxy methyl cellulose sodium) as well as a moisture-insoluble outer membrane polymer (e. g., Eudragit ® RL). GI fluid External membrane stimulation allows the expansion of inflammatory factor agent. The ensuing pressure because of swelling force results in membrane disruption and subsequent rapid release of drugs. Different grades of viscosity of hydroxyl propyl methyl cellulose, polymethyl methacrylate, polyvinyl acetate and polyethylene oxide were used for the design of the hydrogel plug. A delayed-release media-coated device (ETP tablets) was another new method [49-52].

\section{Diffucaps $®$ technology}

Differences of $\mathrm{pH}$ influence their bioavailability or digestion of some medications across the gastrointestinal tract. This $\mathrm{pH}$ dependency may cause problems, especially when a continuous or controlled released mechanism was developed. Carvedilol and dipyridamole were drugs which are belly-soluble yet unsolvable throughout the intestine's neutral/slightly alkaline environments whereby actual 
drug penetration is optimal. Poor specific product substances are of great concern, that are unsolvable at such a pH higher than five. Diffucaps technology enables the growth and advertising of contemporary, regulated-release delivery systems of substantial $\mathrm{pH}$ dependent soluble profiles or low bioavailability in biological fluids of single-or twice-daily dose of single medications and drug formulations. A proprietary technology has been developed specifically of soft, basic medications concerning its inclusion of pharmaceutically appropriate chemical acids or maybe even a decomposition which prevents resin onto sterile centers or covers the alcohol-layered particles of proprietary active composites. Formulas to use an acidic core ensure that perhaps the medication is often accompanied by such an arid environment, thus creating a soluble product in the in situ atmosphere where it could be intractable [53-55].

Diffucaps is indeed a dual-particular beads arrangement composed of multiple release controlled drug sheets excipients, and polymers. The beads comprise a layer of organic acids or alkaline solution which regulate the bioavailability of the drug by creating an optimum $\mathrm{pH}$ microenvironment for medicines which are poorly soluble in gastrointestinal $\mathrm{pH}, \mathrm{pH}$ environments beyond 8.0 or biological liquids. Its size of the Diffucaps beads is $<1.5 \mathrm{~mm}$ and it can be loaded in capsules or compressed to tablets that degrade internally. Patients of difficulty swallowing tablets or capsules Diffucaps products in capsules therefore require a capsule to also be opened and the content used in the spray on foods to provide such a versatile type of dosage. A flexibility of a Diffucaps system will make altering the launch profile and dosing concentration simple to accomplish necessary in vivo results. Such versatility simplifies dose-ranging trials for clinical trial between drug development partners, as the beads can be encapsulated individually to create separate test arms [56].

\section{CODAS $®$ technology}

During some situations, it is not possible to release the drug immediately. For a variety of reasons, a delay in drug intervention may be needed. Chronotherapy is an instance of a launch of medications may be scheduled following administration after the extended period. To achieve this extended duration, Élan Medication may have evolved CODAS $₫$. CODAS $₫$ technology benefits, such as the distribution design of CODAS $\AA$, including account in transmission designed for complement circular patterns, regulated begin-up, sustained release process, release basically acidity, positioning or food independent, "spray" dosage by removing the capsule and spraying food content, decreased active every day dosage and medication intake, local impact targeting of the gastrointestinal tract and decreased structural directed profile sensitivity [57-59].

\section{Verelan $®$ PM}

The delivery system, which is regulated, results in the morning hours of maximum verapamil plasma concentration (Cmax). These pelletfilled capsules provide in the gastrointestinal tract for the extended drug launch. The formulation of Verelan $₫$ PM was formulated to activate verapamil release four-five hours going to follow absorption. Such lag is caused and applied to drug-charged beads by the level of semi-enteric-controlled polymer launch [60]. A mixture of moisturesoluble and water-insoluble polymers was the launch-controlling polymer. As water comes into contact with the polymer-coated beads from the gastrointestinal tract, the water-soluble polymer gradually dissolves and the substance spreads through the pores of the coating. The water-insoluble polymer remains a barrier, maintaining the drug's controlled release. The release rate is largely independent of Temp, body position and dietary autonomous. It was shown which multi particulate technologies like Verelan $₫$ PM are free of gastric kidney function [61-63].

\section{OROS® technology}

For drugs that are poorly soluble in water, OROS delivery system has been implemented. The push pull system consists of a tablet core with a bi-layer or tri-layer consisting of a layer of push and one or even more layers with drugs. A medicine surface includes drugs, osmotic agents and binding agents that are poorly soluble. Among other stuff, the push layer includes osmotic agent, water-swelling polymers.

On the tablet core a semi-permeable membrane is surrounded. A Number of OROS $₫$ systems was developed (ALZA Corp.), ; like Procardia XL $®$, Ditropan XL $®$ or Concerta $®$. A new advanced version delivery system L--SOFTCAPTM OROS $®$ incorporates a function delivery system L-OROS $₫$ SOFTCAPTM incorporates the functionality of a checked release and improved system of distribution with bioavailability to increase adherence and rehabilitation impact [64-66].

L-OROSTM technology was developed to overcome the problem of drug solubility. Other Formulations include self-emulsifying liquid carrier (SEF) formulations that facilitate the absorption of the drug over the tissue and also the intestinal bloodstream. The systems of $P$ e-OROS, the SEF contains drugs generated in semi watering fluid carriers for supply a nanosuspension or even a solution. Since drugs are released in the GI tract in solution, they form very little droplets $(<100 \mathrm{~nm})$, which increase drug osmotic pressure and thus enhance bioavailability [67].

\section{Geomatrix TM}

For the constant launch of medications depending on Geomatrix ${ }^{\circledR}$ technology, a new distribution system in the form of a multilayer tablet has recently been suggested. This is an active core matrix of hydrophilic. This comprises of a hydrophilic matrix membrane comprising the main ingredient or one or two impervious or nonpermeable coatings of polymer (film or light weight barrier) applied one or both core bases. A Geomatrix TM technique is being used to obtain individual concentrations of slow release of specific drugs and it is possible to achieve its simultaneous release in two different drugs from a single tablet at different rates. The presence of the coatings increases the core's hydration/welling level and reduces the available surface area for drug release. Such partial coatings provide a regulation of the drug dissolution profile, i.e. they reduce the device's release speed and change the normal time-dependent release level to a constant release of drugs. The benefits of Geomatrix TM technology is their ability to be readily incorporated in to the production line, they could be produced using available machinery, repeatability, efficiency, flexibility of launch mechanisms, controlled release of poorly soluble medications, timely release of medications, launch of two or even more medications at various rates, pulsed release of drugs, safety of use [68-70].

\section{Minitablets ${ }^{\circledR}$}

Eur and Minitabs are small cylindrical tablets to regulate the speed of medication release. Eur and Minitablets contain gel excipient that controls the speed at which drugs are released. In order to further regulate the release speed, additional membranes may be added. The tablets are packaged in capsules allowing a combination of multiple medication or discharge profiles in same dose type. Before further coating, it is possible to formulate Eur and Minitabs as tablets of matrix. It is also possible to use Eur and Minitabs as a meat sprinkle. Eur and Minitabs combines versatility in tablet design with the complexity of multi particulate systems that can be used as a tablet-swallowing sprinkler for patients $[66,71]$.

\section{Opana ${ }^{\circledR}$ ER technology}

Opana ER is recommended in patients having continuous opioid therapy near the clock for the long-term treatment of moderate to severe pain. Since its approval in 2006, Patients with mild to moderate chronic pain have also been handled with Opana ${ }^{\circledR}$ ER circumstances like chronic lower back pain and osteoarthritis. Several changes have been made to the Opana ER phone. Opana ER was available in "biconvex" tablet form in 2011, and elevated and close-up on both ends. There may be quantities which are limited available through your local pharmacy of both Opana ER's biconvex tablets and the octagonal initial formulation tablet [72-75].

\section{PRODAS ®technology}

Programmable Oral Drug Absorption System (PRODAS (RTechnology) is a multi particular technology that integrates the 
advantages of a tablet system into a capsule. Quite versatile, it is possible to use PRODAS $\AA$ software to pre-program a drug's release speed [76]. It is possible to integrate several different minitablets, each uniquely designed and programmed in the gastrointestinal tract to release drugs at different sites. Minitablets of different sizes can also be integrated. So, it is possible to charge high amounts of drugs [77].

\section{SODAS $®$ technology}

Elan's multi particulate drug supply system is SODAS $₫$ (Spheroidal Oral Drug Absorption System). The SODAS $₫$ technology is distinguished by its inherent versatility based on the development of controlled release beads, enabling the production of personalized dosage forms that respond directly to the needs of individual drug candidates $[64,78]$. Elan's SODAS $®$ Technology focuses on the manufacture of 1-2 $\mathrm{mm}$ diameter uniform spherical beads that contain drug plus excipients and are coated with material-specific controlled release polymers. The new regulatory approvals for a one-day oral dosage formulations based on SODAS $₫$ with the launch of Avinza TM, Ritalin $₫$ LA and Focalin $₫$ XR [79-81].

\section{CONCLUSION}

Oral medication is the major and best favoured route of medication. Generally, sustained and controlled-release products deliver an anticipated beneficial result, but therapeutic effect decreases for diseases or disorders which require medication as per biological rhythms of the disease. As drug release is adjusted according to circadian rhythm of the body, PDDS will successfully eradicate this challenge. Drug delivery to particular location and time is necessary to fulfil the disease's pathophysiological necessity. Number of technologies based on the pulsatile release concept has been designed, developed and marketed by various manufacturers. Yet, unlike commonly used dosage types viz. tablets and capsules; the full-scale commercialization of PDDS remains a problem for the pharmaceutical industry. Unless the pharmaceutical industry can solve the challenges associated with commercialization of PDDS, drug treatment would be more successful with full therapeutic benefit and limited adverse effect for certain highly prevalent diseases or disorders in the population worldwide.

\section{ACKNOWLEDGEMENT}

The authors acknowledge Acharya and BM Reddy College of Pharmacy, Bengaluru for providing the necessary internet and library facilities and support to complete the work.

\section{FUNDING}

Nil

\section{AUTHORS CONTRIBUTIONS}

All the authors have contributed equally.

\section{CONFLICTS OF INTERESTS}

The authors declare no conflicts of interest.

\section{REFERENCES}

1. Sona SC, Hetal KP, Punit B, Pragna KS. Chrono modulated drug delivery system of urapidil for the treatment of hypertension. J Pharm Res 2015;5:107-13.

2. Mirelabodea, Ioantomuta, Sorin L. Identification of critical formulation variables for obtaining metoprolol tartrate minitablets. Farmacia 2010;58:719-27.

3. Katakam VK, Reddy S, Panakanti PK, Yamsani MR. Design and evaluation of a novel gas formation-based multiple-unit gastroretentive floating drug delivery system for quetiapine fumarate. Trop J Pharma Res 2014;13:489-49.

4. Patwekar SL, Baramade MK. Controlled release approach to novel multi-particulate drug delivery system. Int J Pharm Pharma Sci 2012;4:756-63.

5. Leemer B. Chronopharmacokinetic: implication for drug treatment. J Pharm Pharmacol 1999;51:887-90.

6. Rubinstein A, Tirosh B, Baluom M, Nassar T, David A. The rationale for peptide drug delivery to the colon and the potential of polymeric carriers as effective tools. J Controlled Release 1995;46:59-73.

7. Sayeed A, Hamed M, Rafiq M, Ali N. Pulsatile drug delivery: recent technology. Int J Pharm Sci Res 2013;4:960-9.

8. Rompicharla B, Suria P. A comprehensive review of pulsatile drug delivery system. Int J Pharm Res 2012;3:106-8.

9. Prasanth V, Mitesh P, Modi, Sam T. Pulsatile: a tool for circardian rhythm-a review. J Drug Delivery Ther 2012;2:58-65.

10. Rajput M, Sharma R, Kumar S, Jamil F, Sissodia N. Pulsatile drug delivery system: a review. Int J Res Pharma Biomed Sci 2012;3:118-22.

11. Tolic IM, Mooskeilde E, Sturis J. Modeling the insulin-glucose feedback system: the significance of pulsatile insulin secretion. J Theor Biol 2000;207:361-75.

12. Cohen S, Bernstein H. Eds. Microparticulate systems for the delivery of proteins and vaccines. New York: Marcel Dekker, Inc; 1995.

13. Pandit V, Kumar A, Ashawat MS, Chander P, Verma CP, Kumar P. Recent advancement and technological aspects of pulsatile drug delivery system. Curr Drug Targets 2017;18:1191-203.

14. Krogel I, Bodmeier R. Floating or pulsatile drug delivery systems based on coated effervescent cores. Int J Pharm 1999;187:175-84.

15. Yui N, Okano $\mathrm{T}$, Sakurai $\mathrm{Y}$. Inflammation responsive degradation of crosslinked hyaluronic acid gels. J Controlled Release 1992;22:105-16.

16. Miyata N, Asami T, Uragami. A reversibly antigen responsive hydrogel. Nature 1999;399:766-9.

17. Saslawski O, Weigarten C, Benoit JP. Magnetically responsive microspheres for pulsed delivery of insulin. Life Sci 1988;42:1521-8.

18. Barzegar Jalali M, Siyahi Shadbad M. Design and evaluation of delayed release osmotic capsule of acetaminophen. Iran J Pharma Sci 2006;2:65-72.

19. Linkwitz A, Magruder JA, Merrill S. Osmotically driven delivery device with expandable orifice for pulsatile delivery effect. US Patent 5,318,558; 1994.

20. Balaban SM, Pike JB, Smith JP, Baile CA. Osmotically driven delivery devices with pulsatile effect. US Patent 5,209,746; 1993.

21. Niwa K, Takaya T, Morimoto T, Takada K. Preparation and evaluation of time controlled release capsule made of ethyl cellulose for colon delivery of drugs. J Drug Target 1995;3:83-9.

22. Arora S, Ali J, Ahuja A, Baboota S, Qureshi J. Pulsatile drug delivery systems: an approach for controlled drug delivery. Indian J Pharm Sci 2006;68:295-300.

23. Bussemer T, Dashevsky A, Bodmeier R. A pulsatile drug delivery system based on rupturable coated hard gelatin capsules. J Controlled Release 2003;93:331-9.

24. Krogel I, Bodmeier R. Pulsatile drug release from an insoluble capsule bodycontrolled by an erodible plug. Pharm Res 1998;15:474-81.

25. Krogel I, R Bodmeier R. Evaluation of an enzyme-containing capsular shaped pulsatile drug delivery system. Pharm Res 1999;16:1424-9.

26. Mohamad A, Dashevsky A. pH-independent pulsatile drug delivery system based on hard gelatin capsules and coated with aqueous dispersion Aquacoat@ ECD. Eur J Pharm Biopharm 2006;64:173-9.

27. Pozzi F, Furlani P, Gazzaniga A, Davis SS. The TIME CLOCK system: a new oral dosage form for fast and complete release of drug after predetermined lag time. J Controlled Release 1994;31:99-108.

28. Wilding IR, Davis SS, Pozzi F, Furlani P, Gazzaniga A. Enteric coated timed release systems for colonic targeting. Int J Pharm 1994;111:99-102.

29. Gazzaniga A, Iamartino P, Maffione G, Sangalli ME. Oral delayed-release system for colonic specific delivery. Int J Pharm 1994;2:77-83.

30. Maroni A, Zema L, Cerea M, Sangalli ME. Oral pulsatile drug delivery systems. Expert Opin Drug Delivery 2005;2:855-71.

31. Sangalli ME, Maroni A, Zema L, Busetti C, Giordano F, Gazzaniga A. In vitro and in vivo evaluation of an oral system for time and/or site-specific drug delivery. J Controlled Release 2001;73:103-10. 
32. Conte U, La Manna A, Colombo P. Tablet for pharmaceutical use able to release active substances at successive times. US Patent 4,865,849; 1989.

33. Conte U, Giunchedi P, Maggi L, Sangalli ME, Gazzaniga A, Colombo P, et al. Ibuprofen delayed release dosage forms: a proposal for the preparation of an in vitro/in vivo pulsatile system. Eur J Pharm 1992;38:209-12.

34. Roy P, Shahiwala A. Multiparticulate formulation approach to pulsatile drug delivery: current perspectives. J Controlled Release 2009;134:74-80.

35. Bussemer T, Bodmeier R. Multiparticulate pulsatile drug delivery systems. In: S Benita. Ed. Microencapsulation Methods and Industrial Applications Second Edition, CRC Press: Tyalor and Francis Group, 6000 Broken Sound Parkway NW, Suite 300, Boca Raton, FL 33487-2742; 2006.

36. Krogel I, Bodmeier R. Floating or pulsatile drug delivery systems based on coated effervescent cores. Int J Pharm 1999;187:175-84.

37. Percel P, Vishnupad KS, Venkatesh GM. Timed pulsatile drug delivery systems. US Patent. 6,627,223B2; 2003.

38. Narisawa S, Nagata M, Hirakawa Y, Kobayashi M, Yoshino H. An organic acid induced sigmoidal release system for oral controlled-release preparations. Part II: permeability enhancement of Eudragit RS coating led by the physicochemical interactions with organic acid. J Pharm Sci 1996;85:184-8.

39. Narisawa S, Nagata M, Danyoshi C, Yoshino H, Murata K, Hirakawa $\mathrm{Y}$, et al. An organic acid-induced sigmoidal release system for oral controlled-release preparations. Pharm Res 1994;11:111-6.

40. Bodmeier R, Guo X, Sarabia RE, Skultety P. The influence of buffer species and strength on diltiazem $\mathrm{HCl}$ release from beads coated with aqueous cationic polymer dispersions, Eudragit RS, RL 30D. Pharm Res 1996;13:52-6.

41. Kumar GA, Bhat A, Lakshmi AP, Reddy K. An overview of stimuli-induced pulsatile drug delivery systems. Int J Phys The R 2010;2:2364-78.

42. Sarfaraz Md, Joshi VG. Development and evaluation of enteric coated drug delivery system for treatment of asthma. IOSR J Pharm 2014;4:34-6.

43. Jain D, Raturi R, Jain V, Bansal P, Singh R. Recent technologies in pulsatile drug delivery systems. Biomatter 2011;1:1-9.

44. MacNeil ME, Rashid A, Stevens HN. Dispensing device. World Patent; 1990. p. 9009168.

45. Fukui E, Miyamura N, Uemura K, Kobayashi M. Preparation of enteric coated timed release press-coatedtablets and evaluation of their function by in vitro and in vivo tests for colon targeting. Int J Pharm 2000;204:7-15.

46. Jose S, Dhanya K, Cinu TA, Litty J, Chacko AJ. Colon targeted drug delivery: different approaches. J Young Pharmacist 2009;1:13-9.

47. Patel GC, Patel MM. Developing a modified pulsincap system. Pharm Tech Europe 2009;21.

48. Steve E. Bio-enhancement technologies improve absorption of insoluble drugs in oral dosage forms. Drug Deliv Syst 2007;2:4.

49. Percel P, Vishnupad KS, Venkatesh GM. Timed sustained release systems for Propranolol. US Patent. 2002;6500454.

50. Roy P, Shahiwala A. Multiparticulate formulation approach to pulsatile drug delivery: Current perspectives. J Control Release 2009;134:74-80.

51. Verma RK, Garg S. Current Status of Drug Delivery Technologies and Future Directions. Pharma Technol On-Line 2001;25:1-14.

52. Deng GY, Li-Min Z, Christopher J, Branford W, Xiang LY. Threedimensional printing in pharmaceutics: Promises and problems. J Pharm Sci 2008;97:3666-90.

53. Rowe CW, Katstra WE, Palazzolo RD, Giritlioglu B, Teung P, Cima MJ. Multimechanism oral dosage forms fabricated by three dimensional printing. J ContRele 2000;66:11-7.

54. Katstra WE. Fabrication of complex oral drug delivery forms by Three Dimensional Printing, Massachusetts Institute of Technology 2001;237-41.

55. Panoz DE. Geoghegan A, Edward J. Controlled absorption pharmaceutical composition. US Patent. 1989. 4863742.
56. Troy MH. Timing drug availability with therapeutic need. Speciality Pharma 2006;2:1.

57. Rappar D. Oral extended release: Snapshots and benefits. Drug Delivery Technol 2007; 7:42.

58. Devesh AB, Pethe AM. Lipid technology-a promising drug delivery system for poorly water soluble drugs. Int J Pharm Res Devel 2010;2:1-11.

59. Shram M, Romach M, Sellers E, Thipphawong J. Assessing the abuse potential of an oral osmotic controlled extended release (OROS) hydromorphone compared to immediate release hydromorphone. J Pain 2009;10:45-54.

60. Zentner GM, Rork GS, Himmelstein KJ. The controlled porosity osmotic pump. J Control Release 1985;1:269-82.

61. Elan Corporation. Intestinal protective drug absorption system. US Patent. 1997. 75111480.

62. Shaji J, Chadawar V, Talwalkar P. Multiparticulate Drug Delivery System. The Indian Pharmacist 2007;6:21-8.

63. Steven AG. Bio-therapeutics-from drug discovery to drug delivery. Control release society Newsletter 2004;21:3.

64. Conte U, Colombo P, Maggi L, La MA. Compressed barrier layers for constant drug release in swellable matrix tablets. STP Pharma Sci 1994;4:107-13.

65. Conte U, Maggi L. Modulation of the dissolution profiles from Geomatrix $®$ multi-layer matrix tablets, containing drugs of different solubility. Biomaterials 1996;17:889-96.

66. Conte U, La Manna A, Colombo P. Tablets with controlled-rate release of active substances. US Patent Application; 1992.

67. Ozeki Y, Danjo K. Development of one-step drycoated tablet system (OSDRC-System) and the comparison of its compression characteristics with those of conventional drycoated tablets. J Pharm Sci Technol 2004;5:59-66.

68. Yuichi O, Masaki A, Yukinao W, Kazumi D. Evaluation of novel one-step dry-coated tablets as a platform for delayed-release tablets. J Controlled Release 2004;95:51-60.

69. Yuichi O, Yukinao W, Hirokazu O, Kazumi D. Development of dividable one-step dry-coated tablets (Dividable-OSDRC) and their evaluation as a new platform for controlled drug release. Pharm Res 2004;21:1177-83.

70. Bussemer T, Otto I, Bodmeier R. Pulsatile drug delivery systems. Crit Rev Ther Drug Carrier Syst 2001;18:433-58.

71. Shaji J, Chadawar V, Talwalkar P. Multiparticulate drug delivery system. Indian Pharm 2007;6:21-8.

72. Dey NS, Majumdar S, Rao MEB. Multiparticulate drug delivery systems for controlled release. Trop J Pharm Res 2008;7:1067-75.

73. Shidhaye S, Dhone A, Budhkar T, Surve C. Technologies in pulsatile drug delivery system. Int J Adv Pharm Biol Chem 2012;1:438-42.

74. Jones JW, Francis J. Softgels: consumer perceptions and market impact relative to other oral dosage forms. Adv Ther 2000;17:15-20.

75. Roy P, Shahiwala A. Multiparticulate formulation approach to pulsatile drug delivery: current perspectives. J Controlled Release 2009;134:74-80.

76. Prisant LM, Devane JG, Butler J. A steady-state evaluation of the bioavailability of chrono therapeutic oral drug absorption system verapamil PM after night time dosing versus immediate acting verapamil dosed every $8 \mathrm{~h}$. Am J Ther 2000; 7:345-51.

77. Smith DH, Neutel JM, Weber MA. A new chrono therapeutic oral drug absorption system for verapamil optimizes blood pressure control in the morning. Am J Hypertens 2001;4:14-9.

78. Bussemer T, Otto I, Bodmeier R. Pulsatile drug delivery systems. Crit Rev Ther Drug Carrier Syst 2001;18:433-58.

79. Ueda S, Ibuki R, Kimura S, Murata S, Takahashi T. Development of a novel drug release system, time controlled explosion system (TES). Part III: relation between lag time and membrane thickness. Chem Pharm Bull 1994;42:364-7.

80. Verma RK, Sanjay G. Current status of drug delivery technologies and future directions. Pharma Technol On-Line 2001;25:1-14.

81. Venkatesh G. Diffucaps technology for controlled release drug delivery. In: Youan BC. ed. Chronotherapeutics: science and technology for biological rhythm guided therapy and prevention of diseases. New York: John Wiley and Sons; 2009. p. $122-42$. 